WHAT WILL YOUR EVENT DO?

Apart from make a genuine impression on your guests, an event at Burlington House will help us to promote, support and celebrate chemistry on a global scale.

YOU MIGHT HELP TO

Make the next big discovery Inspire the next generation Shape new science policy

Tackle the world's challenges

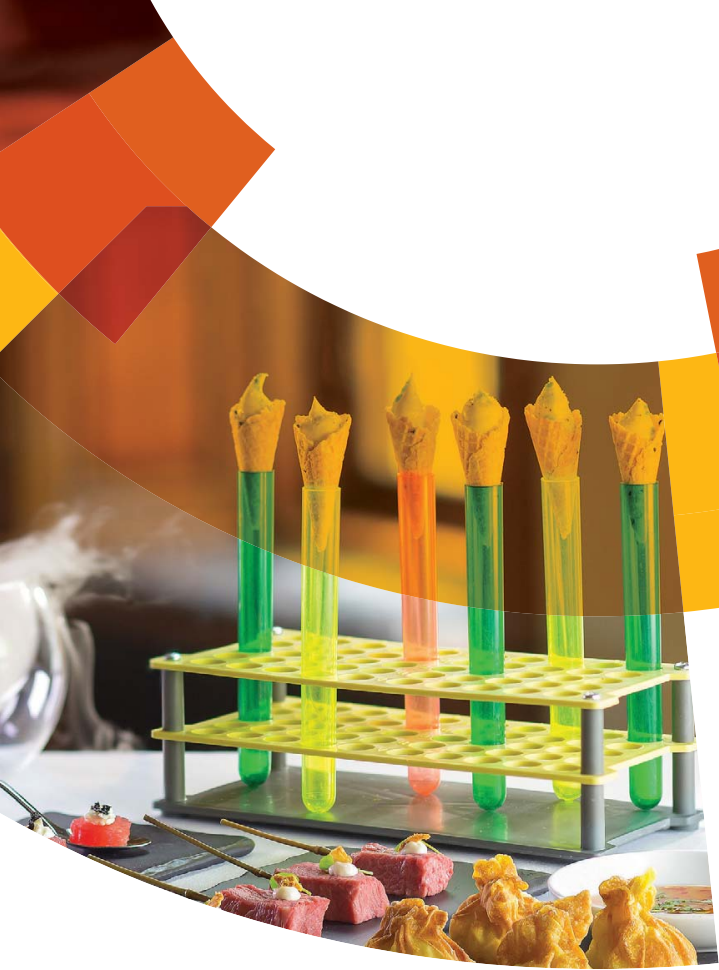

THIS IS VENUE

HIRE WITH A

DIFFERENCE

FOR A PERSONALISED QUOTE:

02074403352 venuehirearsc.org http://rsc.li/venue 


\section{What is chartered status?}

Experience.

In-depth knowledge. Expertise.

Integrity.

Professionalism.

\section{Dedication.}

Achieving chartered status demonstrates that you have all of these attributes and more.

At the Royal Society of Chemistry, we can help you achieve the professional qualifications that inspire confidence and trust in science and scientists.

\section{Work with us to gain:}

- Chartered Chemist (CChem) - awarded to experienced, practising chemists.

- Chartered Scientist (CSci) - awarded to a range of experienced, practising scientists.

Find out how to apply at http://rsc.li/cchem

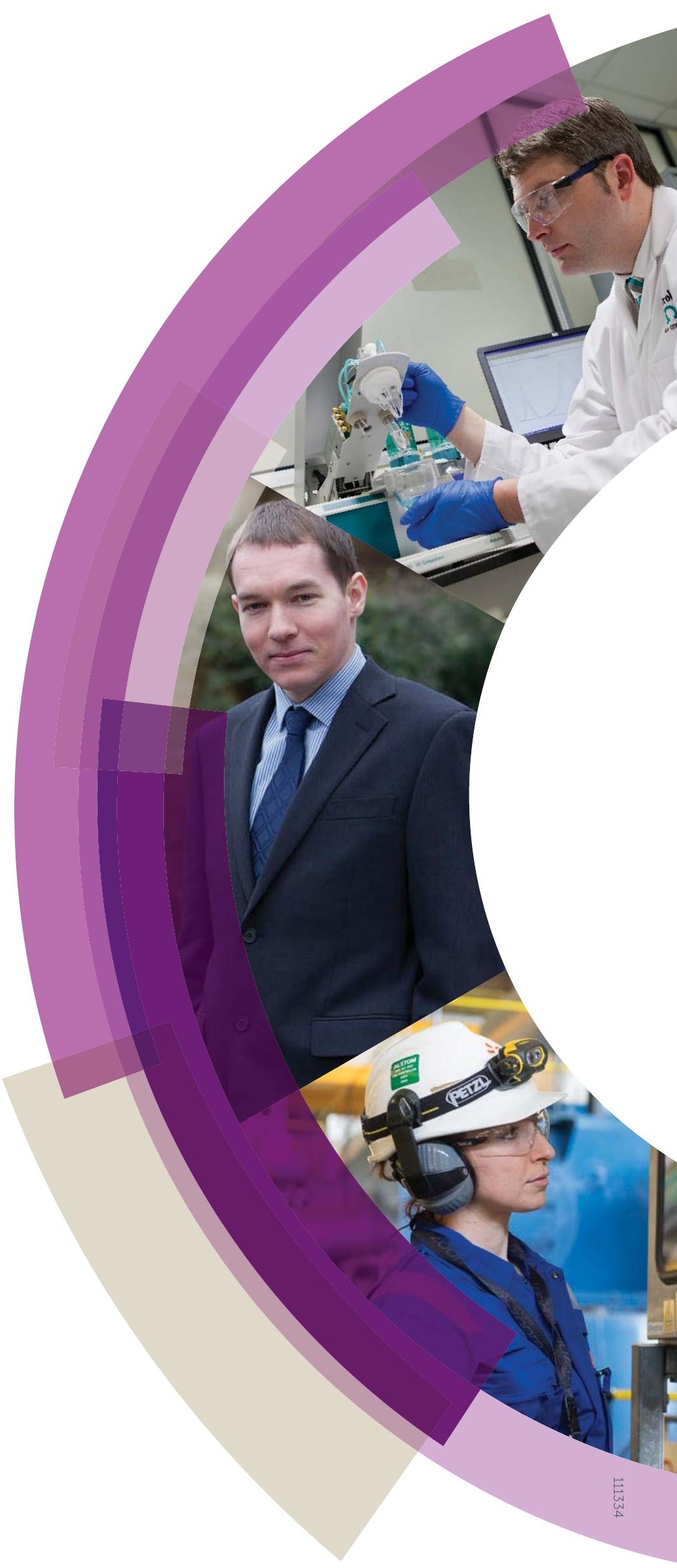

